\title{
A LEITURA URBANA DE LIMA BARRETO \\ EM CLARA DOS ANJOS
}

ADRIANA CARVALHO SILVA'

\section{RESUMO}

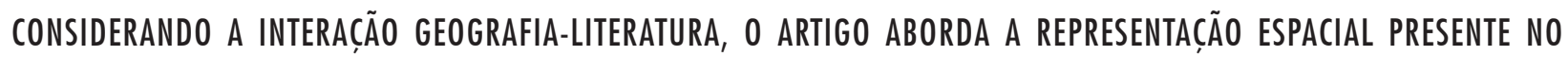
ROMANCE CLARA DOS ANJOS, DE LIMA BARRETO.

EM SEU PRIMEIRO ROMANCE ESBOCADO, O ESCRITOR NOS APRESENTA SUA LEITURA DA CIDADE DO RIO DE JaNEIRO

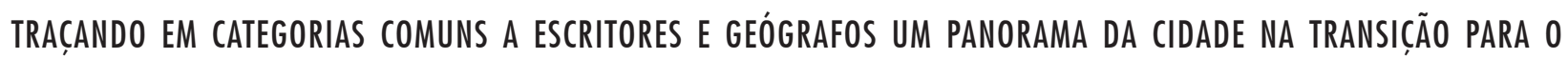
SÉCULO XX.

0 teXTO de LIMA barRetO GUARDA A EXPRESSÃO MÁXIMA DE SUA ESPACIALIDADE E TEMPO E OS CONFLITOS QUE ENVOLVEM SEUS PERSONAGENS ESTÃO NO COTIDIANO URBANO. A CIDAdE dO ROMANCE NASCE DA SENSAÇ̃̃o, VIVÊNCIA, PERCEPÇÃO E CONCEPÇÃO DO AUTOR E CONSIITUI SUA EXPERIÊNCIA COM $O$ LUGAR.

PalaVRAS-CHAVE: REPRESENTAÇÃO, LUGAR, CIDADE.

- romance Clara dos Anjos começa a ser escrito em 1904 e, embora não passe do roteiro, dois capítulos inteiros e o esboço de mais dois ou três nasceu da intenção do autor de escrever uma obra notável sobre a história da escravidão negra no Brasil.

O livro só foi concluído entre 1920 e 1922 e Lima Barreto não o viu publicado. O romance já não seguia o esboço original. No entanto, o próprio autor afirma: "Saiu coisa bem diferente, se bem que o fundo seja o mesmo" ${ }^{\prime \prime}$.

Nas duas versões Clara é vítima da sua condição de mulher, negra e pobre. A história é a mesma: a jovem mulata que se deixa perder por um rapaz de condição superior à sua, branco, o qual recusa o casamento para consertar o malfeito.
O Rio de Janeiro da primeira versão é o de antes da Abolição da escravatura. A ação se desenvolve até o regime republicano, por volta de 1904 e 1905. Clara é "deflorada" no ano seguinte à morte do pai, no dia 12 ou 13 de maio, a própria data da Abolição.

Nessa primeira versão de Clara dos Anjos Lima Barreto descreve a formação da cidade, o papel dos meios de transporte na expansão urbana, destacando a segregação espacial reproduzida pelos bondes e trens. As habitações compõem o panorama que abriga os personagens do romance e entre os operários e outros cavalheiros citados, podemos reconhecer o tipo que representaria o antiherói, o violeiro chamado Cassi Jones na versão 
da década de vinte. A abertura do livro está aqui na íntegra. Vejamos o Rio de Janeiro retratado pelo autor para compor a história da jovem mulata:

A cidade do Rio de Janeiro é regularmente edificada. Não se infira daí que ela o seja conforme o estabelecido na teoria das perpendicularidades e oblíquas; antes se conclua que a cidade se tem erguido, acorde com a topografia do local onde se assentou e com as vicissitudes históricas que sofreu.

Se não é regular com a estreita geometria de um agrimensor, é, entretanto, com as colinas que a distinguem e fazem-na formosa. Enquadra-se guarridamente nelas, explicando-as e continuando-as.

Ao nascer, no topo do Castelo, não foi mais do que um escolbo branco surgindo num revolto mar de bosques e brejos. Aumentando, desceu pela venerável colina abaixo; coleou-se pelas várzeas em ruas estreitas. Anecessidade da defesa externa, de alguma forma, obrigou-as a ser assim e a polícia recíproca dos babitantes contra malfeitores prováveis fê-las continuar do mesmo modo, quando, de piratas, pouco se tinba a temer.

A quilombola e o corsário projetaram a cidade. Surpreendida coma descoberta das lavras de Minas, que fizeram dela entreposto, a velba São Sebastião aterrou apressada alduns brejos, para aumentar e espraiar-se, e todo o material foi-lhe útil para tal fim.

A população, preguiçosa de subir de novo morros, construiu sobre um solo de cisco e o rei Dom João veio descobrir praias e arredores cheios de encantos, cuja existência ingenuamente ig- norava. Uma cousa compenson a outra ${ }_{i}$ e logo que a Corte quis firmar-se e tomar ares solenes... Quem observa uma carta do Rio e tem de sua antiga topografia modestas notícias, define plenamente as preguiçosas sinuosidades de suas ruas e as imprevistas dilatações que elas oferecem. Ali, uma ponta de montanbas empurrouas; aqui, um alagadiço dividiu-as em duas azinhas simétricas, deixando-o intacto à espera de um lento aterro.

$\mathrm{Na}$ fisionomia das casas esteriotipam-se as cousas da nossa bistória. Um observador amoroso e perspicaz não precisa ler, ao alto, a data entre os ornatos de estuque, para saber quando uma delas foi edificada. Esse casarão de dois andares que vemos na rua do Sabão ou da Alfândega, é dos primeiros quinze anos da Independência. Vede-lhe a segurança afetada; a força demasiada das paredes, a valentia dos alicerces que se advinba... Quem a fez, sabia das luta do Primeiro Reinado, vinba seguro de possuir uma terra sua para viver a vida eterna da descendência. O tráfico de escravos imprimiu ao Valongo e aos morros da Saúde alguma cousa de cubata africana, e a tristeza do cais dos Mineiros é saudade das ricas faluas que não chegam mais a Inhomirim e da Estrela, pejadas de mercadorias.

O bonde, porém, perturbou essa metódica superposição de camadas. Hoje, o geólogo de cidades atormenta-se com o aspecto transtornado dos bairros. Não bá mais terrenos paralelos; as estratificações inclinam-se; os depósitos baratham-se $e_{i}$ a divisão da riqueza e novas instituições sociais ajudam o bonde nesse trabalbo platônico. 
No entanto, este veículo alastra a cidade, cria na ponta de seus trilhos núcleos de condensação urbana. Onde ele chega, desenba-se uma venda, surge um botequim, um quiosque; em torno, edificam-se casebres. Ondulações concêntricas a esse núcleo encontram as de outro próximo, dando nascimento a uma travessa mal povoada, tristonba, esquecida das autoridades municipais, e que vive anarquisadamente, fora de toda a espécie de legislação, a poucas centenas de metros de outras, apertadas num cinto de posturas.

Por elas, o capim medra viril e orgulhoso; os cabritos desembaraçadamente pastam; as lavadeiras sem cerimônia coram as roupas; $e$ as poucas casas que bá, besitam entre a casa e o casebre e dão-se ao luxo de ter jardim na frente. As casas em geral isoladas, separadas umas das outras, por cercas de espinbeiros ou bambús, mas, às vezes, juntam-se em grupo, cavalgam-se umas às outras, de jeito que, quem as vê, considera a extensão de terra e a muita que por aqueles lugares sobra.

A população que as povoa é betereoclítica. $\mathrm{Na}$ generalidade, operários e pequenos empregados; mas, se algum descuidado se aventura por uma dessas travessas adentro, surpreender-se-á sem razão ao cruzar com algum elegante da rua do Ouvidor.

Cavalbeiros de extraordinária exuberância amorosa, e de apoucados rendimentos, resolvem o problema de sua natureza, gastando com a família o mínimo, num desses corredores, e o máximo, nos alfaiates e aperitivos platônicos com as cocotes nas confeitarias.
O Rio de Janeiro por onde percorrem o autor e seus personagens, espaço em transição de cidade colonial a cidade remodelada do século XX, é o cotidiano carioca que Lima Barreto representa em Clara dos Anjos na segunda versão.

O ambiente experienciado pelo autor literário, seus passeios de bonde pelos bairros da cidade em visitas a amigos, seu trajeto para o trabalho, fatos que marcam o seu cotidiano e as suas caminhadas pelas ruas do centro da cidade estão relatados por seus personagens.

O escritor Lima Barreto consome experiências, emoções, linguagem, memória e produz o texto, fruto de sua escolhas.

Se a primeira versão tivesse sido concluída no início século $\mathrm{XX}$, dificilmente seria o romance que consagraria o autor naquela época, pois a produção literária era comumente apreciada como reflexo da ordem social, em que o referencial principal do discurso se mostrava exterior ao autor, ficando direcionado à nação. Poucos autores buscavam formas alternativas para pensar a relação literatura- sociedade. Os que optavam por conduzir obras com esse intuito não podiam esperar consagração (Broca, 2004).

Podemos considerar, nessa perspectiva, Lima Barreto. Sua escrita, de vanguarda, era apontada como autobiográfica demais por tratar de um universo pessoal, por abordar questões e dilemas próprios. Clara dos Anjos fala sobre o racismo e a condição feminina, traz o Rio de Janeiro dos subúrbios abandonado pelo poder público com um transporte público precário e uma massa de população subempregada e desempregada a inchar as margens da linha férrea.

Esse era o Rio de Janeiro do cotidiano do escritor, morador do subúrbio, de família humilde 
que dizia-se vítima do preconceito racial e lamentava não ver reconhecidas sua formação intelectual e capacidade produtiva (Diário Íntimo, 1993).

Envolto em uma vanguarda literária de sua época - o naturalismo francês - e ainda na estética de influência marcada por Eça de Queirós, Lima Barreto procura captar o máximo de realidade e compor com o mínimo de ficção, elaborada em caricaturas e ironias, valorizando uma tônica confessional.

O romance que se passa no subúrbio carioca abriga histórias que estão no real concreto vivido pelo autor.

Afonso Henriques de Lima Barreto nasceu em 13 de maio de 1881 . O pai era tipógrafo e a mãe, professora, morre ainda jovem, acometida por tuberculose quando Lima Barreto tinha entre seis e sete anos, sendo o autor o mais velho dos quatro irmãos.

Lima Barreto não chega a completar o curso superior de engenharia na Escola Politécnica, abandonando-o em 1902, ano em que seu pai adoece mentalmente. Nesse mesmo período, Lima Barreto começa a escrever para jornais e ingressa no funcionalismo público. Tornara-se arrimo de família.

O compromisso com o trabalho burocrático não o afasta dos ambientes literários. Ele frequenta os cafés, livrarias e jornais do Rio de Janeiro e ingressa no jornalismo profissional em 1905 no Correio da Manhã. Os artigos de Lima Barreto se destacam e, apesar de toda sua dedicação em tornar-se um escritor consagrado, o autor não consegue viver das letras como gostaria, mesmo depois de se aposentar, com a saúde comprometida pelo alcoolismo: " a minha aposentadoria dá-me uma migalha, com que mal me daria para viver. A minha pena só me pode dar dinheiro escrevendo banalidades para revistas de segunda ordem"2.
Lima Barreto esteve internado por duas vezes no Hospício Nacional, em 1914 e 1919, acometido pelo alcoolismo. Contudo, foi vasta a produção do autor nesse período, sendo candidato a Academia Brasileira de Letras por três vezes, em 1917, 1919 e 1921, tendo retirado sua última candidatura.

Sobre a Academia de Letras, representação do que Lima Barreto criticava enquanto literatura, o autor menciona em carta a Monteiro Lobato: "Sei bem que não dou para a Academia e a reputação de minha vida não se coaduna com a sua respeitabilidade... Como é que podia pretender a Academia? Decerto não.." ${ }^{\prime 3}$

Sem espaço na Academia, o autor ganha destaque em edições póstumas. Lima Barreto morre em novembro de 1922, uma semana antes da Semana de Arte Moderna, aos 41 anos.

É o próprio espaço-tempo de Lima Barreto e a percepção acerca de seu lugar-cidade que compõem o romance Clara dos Anjos. Os dilemas do subúrbio, as reformas urbanas e a sociedade representada na sua espacialidade refletida em conflitos estão no romance que se passa no próprio ambiente do autor. Aqui estão as viagens de trem, os operários, a população que vive ao longo das estações ferroviárias, os subúrbios de Inhaúma, Todos os Santos, Engenho Novo, Méier,... Cidade que concentra um grande volume de produção literária da época, o Rio de Janeiro é objeto de leitura de Lima Barreto.

Que diferença há entre a descrição do subúrbio por Lima Barreto em Clara dos Anjos e o subúrbio real, vivido pelo escritor no século $\mathrm{XX}$ ?

A literatura nos fornece mais do que um olhar sobre a representação do escritor, nos dá ainda uma 
expectativa do que poderia vir a ser real, a estar posto como concreto. $\mathrm{O}$ escritor não se ocupa necessariamente de uma realidade, mas de múltiplas possibilidades, de uma história que não ocorreu, de planos que não se concretizam, todos porém produtos de situações concretas de carências e privações, de expectativas e desejos, situados num âmbito social.

Pode-se portanto pensar em uma representação dos desejos não consumados, dos possíveis não realizados, das idéias não consumidas, em uma história e uma ordenação espacial que ficaram marginais ao sucesso dos fatos, mas nem por isso ausentes (Sevcenko, 1989).

Através de um romance, uma forma específica de representação do espaço geográfico se coloca, de acordo com a ótica e as vivências do autor, e ainda o leitor do romance apreende uma outra forma de representação, que é resultado da interação entre a imagem espacial herdada por ele, segundo suas vivências e informações, e o que é representado pelo autor (Tuan, 1980).

Desta forma, a cidade do Rio de Janeiro do romance Clara dos Anjos é composta por lugares experienciados intensamente pelos personagens num sentido topofílico.

Pensando nas suas próprias andanças e observações Lima Barreto escreve em Clara dos Anjos os dissabores de quem não tem outra opção de moradia além da periferia distante, situada já fora dos limites municipais:

Toda essa gente que vai morar para as bandas de Maxabomba (atual Nova Iguaçu) e adjacências, só é levada a isso pela relativa modicidade do aluguel de casa. Aquela zona não thes oferece outra vantagem. Tudo é tão caro como no subúrbio, propriamente. Não bá água, ou onde bá, é ainda nos lugarejos públicos do Distrito Federal que o governo federal caridosamente supre em algumas bicas públicas, não bá esgotos, não bá médicos, não há farmácias. Ainda dentro do Rio de Janeiro, bá algumas estradas construídas pela Prefeitura, que se podem considerar como tal; mas, logo que se chega ao Estado, tudo falta, nem nada bá embrionário.(...)

Os córregos são em geral valas de lama pútrida, que quando chegam as grandes chuvas, se transformam em torrentes, a carregar os mais nauseabundos detritos. A tabatinga impermeável, o barro compacto e a falta d'água não permitem a existência de bortas; e um repolbo é lá mais raro que no avenida Central (...). A rua em que estava situada a sua casa desenvolviase no plano e, quando chovia, encharcava e ficava que nem um pântano; entretanto era povoada e se fazia caminho obrigatório nas margens da Central para a longinqua e babitada freguesia de Inbaúma. Carroções, carros, caminhões que, quase diariamente, andam por aquelas bandas (...) indicando que tal via pública devia merecer mais atenção da edilidade (...). O Rio de Janeiro, que tem, na fronte, na parte anterior, um tão lindo diadema de montanhas e árvores, não consegue fazề-lo coroa e cingi-lo todo em roda. A parte posterior, como se vê, não chega a ser um neobarbante que prenda dignamente o diadema que lhe cinge a testa olimpica... (Clara dos Anjos, p. 92).

Clara dos Anjos possui uma longa descrição do subúrbio, no seu estado de "abandono" pelo po- 
der público. Lima Barreto protesta. Há indignação e revolta no panorama montado pelo escritor quando nos situa na estação ferroviária do Méier, onde se encontra o personagem Cassi Jones:

O subúrbio propriamente dito é uma longa faixa de que se alonga, desde o Rocha ou São Francisco Xavier, até Sapopemba, tendo para eixo a linba férrea da Central...

Há casas, casinhas, casebres, barracões e choças por toda parte onde se possa fincar quatro estacas de pau e uni-las por paredes duvidosas...(..)

Há verdadeiros aldeamentos dessas barracas, nas coroas dos morros, que as árvores e os bambuais escondem aos olhos dos transeuntes. Nelas, bá quase sempre uma bica para todos os babitantes e nenbuma espécie de esgoto. Toda essa população, pobríssima, vive sob a ameaça constante da varíola e, quando ela dá para aquelas bandas, é um verdadeiro flagelo...(...) Afastando-se do eixo da zona suburbana, logo o aspecto das ruas muda. Não bá mais grades de ferro, nem casas com tendências aristocráticas: bá o barracão, a choça, e uma ou outra casa que tal. Tudo isto muito espaçado e separado; entretanto, encontramse por vezes, "corredores" de pequenas casas, de duas janelas e porta ao centro, formando o que chamamos "avenida".

As ruas distantes da linba da Central vivem cheias de tabuleiros de grama e de capim, que são aproveitados pelas famílias para coradouro. De manhã até a noite, ficam povoadas de toda a espécie de pequenos animais domésticos: galinba, patos, marrecos, cabritos, car- neiros e porcos, sem se esquecer os cães, que com todos aqueles, fraternizavam. (Clara dos Anjos, p.90).

Mas é o ambiente do centro da cidade que chama sua atenção e o atrai. É comum o relato de caminhadas pelas ruas, cafés e visitas a casas de amigos nessa área da cidade. Os passeios pelos bairros do Leme aos domingos eram também muito apreciados pelo número de vezes em que o autor os descreve em seu diário. Ele chegou a viver por lá quando criança, com a mãe ainda viva, depois com o pai na rua do Riachuelo e mais tarde em pensões durante os estudos na escola Politécnica. Conhecia bem todos os caminhos e becos, lugares de fina conduta, bem frequentados pela gente da aristocracia e os desprovidos de qualquer honra e glória, bem como as ruelas que pareciam ter os dias contados pela onda da modernidade remodeladora.

Observar como essa gente vivia parecia um exercício para o literato. Talvez formasse assim seus personagens, ao menos é o que parece quando vemos em seus escritos íntimos, frases "soltas", anotações de nomes e ocupações para alguns possíveis personagens, e ainda temas que o interessavam para compor enredos de algumas histórias. Foi assim que nasceu e tomou forma o romance Clara dos Anjos.

Nesse romance, o personagem Cassi Jones, violeiro que desonrava moças ingênuas e pobres, percorre as ruas do centro da cidade numa de suas estripulias:

\footnotetext{
...procurou alcançar o Largo São Francisco, atravessando aqueles velhos becos imundos que
} 
se originam da Rua da Misericórdia e vão morrer na Rua Dom Manuel e Largo do Moura. Penetrou naquela vetusta parte da cidade, logo povoada de lôbregas hospedarias mas que já passou por sua época de relativo realce e brilho. Os botequins e tascas estavam povoados do que bá de mais sórdido na nossa população. Aqueles becos escuros, guarnecidos, de um e de outro lado, por altos sobrados, de cujas janelas pendiam peças de roupas a enxugar, mal varridos, pouco transitados, formavam uma estranba cidade à parte, onde se iam refugiar bomens $e$ mulberes que baviam caído na mais baixa degradação e jaziam no último degrau da sociedade. Escondiam na sombra daquelas betesgas coloniais, nas alcovas sem luz daqueles sobrados, nos fundos caliginosos das sórdidas tavernas daquele tristonbo quarteirão, a sua miséria, o seu opróbrio, a sua infinita infelicidade de deserdados de tudo desse mundo. (Clara dos Anjos, p.145)

O sedutor Cassi Jones, assim, foi enviado pelos pais à casa de parentes em Guaratiba depois de mais um episódio marcante e trágico de suas conquistas: "foi passar uns tempos na casa do tio, o doutor, que tinha uma fazendola em Guaratiba". Tudo para tentar reverter o comportamento irregular do desajustado membro da família.

Como em outras ocasiões, aqui a vida do autor tem proximidade com a trama. Lima Barreto também foi enviado pela família a Guaratiba, para a casa de seu tio Bernardino, onde passaria o tempo necessário para a cura de seu primeiro delírio, momento que o levou ao hospício pela primeira vez. As lembranças desse episódio marcaram o es- critor. A idéia da família em recorrer ao parente distante e ao hospício tomou forma nas letras.

Ao ler no jornal sobre um conquistador que "seduziu" uma porção de senhoras e "deflorou" onze moças, Lima Barreto transcreve para seu diário as cartas do sedutor que confessava-se um "infeliz que tanto lhe adora e lamenta não ser correspondido" e ainda completava com: "enfim que eu devo fazer se você não quer ser inteiramente minha como eu sou teu". Lima Barreto anota dados sobre as histórias e aí estão as cartas e muitas das picaretagens para compor o perfil do sedutor Cassi Jones, o moço que ilude a jovem Clara dos Anjos.

Cassi era um rapaz, como define o próprio autor, "de pouco menos de trinta anos, branco, sardento, insignificante, de rosto e de corpo" e, embora fosse conhecido como "modinhoso", entre outras façanhas, "não tinha as melenas do virtuose do violão, nem outro qualquer traço de capadócio". Era protegido pela mãe, que " numa de suas crises de vaidade, dizia-se descendente de um fantástico Lord Jones". Não trabalhava, vivia de criar galos, freqüentar rinhas e aplicar pequenos golpes. A polícia o conhecia, mas nunca conseguia mantê-lo preso, pois a família, com insistência da mãe, sempre acabava intervindo com advogados e como as famílias das suas vítimas eram sempre pobres, às vezes moças órfãs de pai, todas humildes, terminavam humilhadas, sem o reconhecimento da injúria e do malfeito.

Lima Barreto traz no personagem Cassi Jones o " tipo mais completo de vagabundo doméstico que se pode imaginar. É um tipo bem brasileiro", acobertado pela sociedade.

O conquistador suburbano criado por Lima Barreto não se sentia à vontade no centro da cida- 
de-capital. Ali, a cidade o engolia, estava longe do seu lugar, do mundo que conhecia e dominava. Não se sentia confortável em ver aquela gente que o fazia parecer insignificante. Cassi Jones compõe um tipo identificado por Lima Barreto de indivíduos que são populares nos subúrbios, e até gozam de certo prestígio, mas minguam no ambiente do centro da cidade, onde não têm reconhecimento algum. Lima Barreto descreve:

Vestia-se seriamente, segundo as modas da rua do Ouvidor, mas, pelo apuro forçado e o degagé suburbanos, as suas roupas chamavam a atenção dos outros, que teimavam em descobrir aquele aperfeiçoadíssimo "Brandão", das margens da Central, que the talbava as roupas.

E ainda:

Não gostava mesmo do centro. Implicava com aqueles elegantes que se postavam nas esquinas e nas calçadas. Achava-os ridículos, exibindo luxo de bengalas, anéis e pulseiras de relógios. É verdade, pensava consigo, que ele usava tudo aquilo; mas era com modéstia, não se exibia. Recordava que não tinba posses, mas mesmo que as tivesse, não se daria a tal ridículo...Essa sua filosofia sobre elegância, de elegante suburbano, ele aplicava à moças. Quanto dengue! (Clara dos Anjos, p. 142)

E também:

Cassi Jones, sem mais percalços, se viu lançado em pleno Campo de Sant'ana, no meio da multidão que jorrava das portas da Central, cheia da bonesta pressa de quem vai trabalhar. A sua sensação era que estava numa cidade estranba. No subúrbio, tinba os seus ódios e os seus amores; no subúrbio tinba os seus companbeiros, e sua fama de violeiro percorria todo ele, e, em qualquer parte, era apontado; no subúrbio, enfim, ele tinha personalidade, era bem Cassi Jones de Azevedo, mas, ali, sobretudo do Campo de Sant'ana para baixo, o que era ele? Não era nada. Onde acabam os trilhos da Central, acaba a sua fama e o seu valimento; a sua fanfarronice evaporavase, e representava-se a si mesmo como esmagado por aqueles "caras" todos, que nem olbavam. (Clara dos Anjos, p.143).

Usuário desse meio de transporte, era nos passageiros de trem que o autor se fixava em suas viagens. Lima Barreto adotava-os para seus personagens, como o faz em Clara dos Anjos:

Pelas primeiras horas da manbã, de todas as bibocas, alforjas, trilhos, morros, travessas, grotas, ruas, sai gente, que se encaminha para a estação mais próxima, alguns morando mais longe, em Inbaúma, em Caxambi, em Jacarepaguá, perdem amor a alguns nídueis e tomam bondes que chegam cheios às estações. Esse movimento dura até às dez horas da manbã e bá toda uma população de certo ponto da cidade no número dos que nele tomam parte. São operários, pequenos empregados, militares de todas as patentes, inferiores de milícias prestantes, funcionários públicos e gente que, apesar de bonesta, vive de pequenas transações, do dia-a-dia, em que ganbam penosamente mil-réis. O subúrbio é o refúgio dos infelizes (...) 
Nestas boras, as estações se enchem e os trens descem cheios. Mais cheios, porém, descem os que vêm do limite do Distrito com o Estado do Rio. Esses são os expressos. Há gente em toda parte. O interior dos carros esta apinbado e vãos entre eles como que trazem quase a metade da lotação de um deles. Muitos viajam com um pé num carro e outro no imediato, agarrando-se com as mãos às grades das plataformas. Outros descem para a cidade sentados na escada de acesso para o interior do vagão; e alguns, mais ousados, dependurados no corrimão de ferro com um único pé no estribo do veículo. (Clara dos Anjos, p.92).

Tratar o subúrbio como o "refúgio dos infelizes"! É um sentimento autobiográfico? Lima Barreto não se sentia totalmente integrado à vida suburbana. A viagem de trem, o principal meio de transporte do subúrbio para a cidade, por vezes o distraía em observações que estimulavam suas reflexões e alimentavam a criação do trabalho de escritor e por outras o aborrecia. O modo como os passageiros da primeira classe muitas vezes o observavam causava desconforto e indignação. Estão nas páginas de seu Diário Íntimo - organizado por Francisco de Assis Barbosa - anotações sobre um subúrbio triste, abandonado nos projetos de política urbana e carente de bem feitorias e ao mesmo tempo povoado por uma multidão de mal sucedidos.

\section{NOTAS}

1 Mestre em geografia pela Universidade Federal Fluminense

2 Carta a Almáquio Cirne, em 5-1-1921. Correspondências. BARBOSA. Francisco de Assis. A Vida de Lima Barreto, 2002.
3 Lima Barreto. Diário do Hospício. 1993, p.174.

4 Brito Broca. A Vida Literária no Brasil . 2004, p.40.

REFERÊNCIAS BIBLIOGRÁFICAS

ABREU, Maurício. A evolução Urbana do Rio de Janeiro. Rio de Janeiro: IPLAN- RIO/Zahar. 1987.

BAKHTIN, M. Questões de Literatura e Estética. São Paulo: Hucitec, 1993.

BARBOSA, Francisco de Assis. A vida de Lima Barreto. $8^{\text {a Ed. }}$ Rio de Janeiro: José Olympio, 2002.

BARRETO, Lima. Clara dos Anjos. Rio de Janeiro: Klick Editora, 1995.

BARRETO, Lima. Diário Íntimo. Rio de Janeiro: Graphia Editorial, 1993.

BENCHIMOL, Jaime Larry. Pereira Passos: Um Haussmann Tropical. A renovação urbana na cidade do Rio de Janeiro no início do século XX. Rio de Janeiro: Secretaria Municipal de Cultura, 1992 (Coleção Biblioteca Carioca).

BROCA, Brito. A vida literária no Brasil - 1900. Rio de Janeiro: José Olympio, 2004.

CORRÊA, R. L. \& ROSENDAHL Z.(org). Geografia Cultural: Um século(2). Rio de Janeiro: Editora UERJ, 2000.

CORRÊA, R. L. Geografia Cultural: Passado e Futuro- uma introdução. In: CORRÊA, R. L. \& ROSENDAHL, Z. Manifestações da Cultura no Espaço. Rio de Janeiro: Editora UERJ, 1999

HOLZER, Werther. A Geografia Humanista - sua trajetória de 1950 a 1990. Rio de Janeiro: UFRJ, 1992. Dissertação de Mestrado.

LEFEBVRE, H. La Presence e L'Absence. Paris: Casterman, 1980. Brasiliense, 1979 Lógica Formal, Lógica Dialética. Rio de Janeiro: The Production of Space. Oxford UK \& Cambridge USA: Blackeell,1974.

MELLO, J. B. F. O Rio de Janeiro dos Compositores da Música Popular Brasileira - 1928/1991 - uma introdução à Geografia Humanística. Rio de Janeiro: PPGG/UFRJ, Dissertação de Mestrado.

MONTEIRO, Carlos Augusto de Figueiredo. O mapa e a trama: ensaios sobre o conteúdo geográfico em obras romanescas. Florianópolis: Editora da UFSC, 2002.

MORETTI, Franco. Atlas do romance europeu 1800-1900. Tradução Sandra guardini Vasconcelos. São Paulo: Boitempo, 2003.

PECHMAN, Robert Moses(org.). Othares sobre a cidade. Rio de Janeiro: Editora UFRJ, 1994

POCOCK, D. C. D. Geograpby and Literature. Progress in Human Geography. Institute of British Geographers, 1988.

RESENDE, Beatriz \& VALENÇA, Rachel. Toda Crônica. Lima Barreto 1919-1922. Apresentação e notas de Beatriz Resende; organização de Rachel Valença. Rio de Janeiro: Agir, 2004.

RESENDE, Beatriz. Lima Barreto e o Rio de Janeiro em fragmentos. Rio de Janeiro: Editora UFRJ,1993

SANTOS, Noronha F. A. As freguesias do Rio Antigo. Rio de Janeiro: O Cruzeiro, 1905.

SEVCENKO, Nicolau. A Revolta da Vacina. São Paulo: Scipione, 1993 (Coleção História Em Aberto). 
. (org.) História da Vida Privada no Brasil. Vol.I, São Paulo: Companhia das Letras, 1998.

Literatura como missão: tensões culturais e

criação cultural na Primeira República. São Paulo: Brasiliense, 1989
TUAN, Yi-Fu. Espaço e lugar: a perspectiva da experiência. Tradução de Lívia de Oliveira. São Paulo: Difel,1983.

Topofilia: um estudo da percepção, atitudes e valores do meio ambiente. São Paulo: Difel,1980.

\section{ABSTRACT}

CONSIDERING GEOGRAPHY- LITERATURE INTERACTION, THE ESSAY DEALS WITH SPACIAL REPRESEENTATION FOUND ON THE NOVEL "Clara dOS ANJOS" bY LIMA BaRRETO.

IN HIS FIRST NOVEL, THE WRITE SHOWS US HIS READING ON THE CITY OF RIO DE JANEIRO, DRAWING INTO COMMON CATEGORIES TO WRITERS AND GEOGRAPHERS ONE OUTLINE OF THE TOWN ENTERING THE 20 $0^{\text {TM }}$ CENTURY. HIS TEXT EXPLANINS MAXIMUM EXPRESSION OF HIS SPACIALITY AND TIME, AND CONFLICTS WHICH INVOLVE URBAN EVERY-DAY CHARACTERS. THE NOVEL TOWN IS BORN FROM THE SENSATION, LIVING, PERCEPTION AND INTERPRETATION OF THE AUTHOR AND FORMS HIS EXPERIENCE WITH THE PLACE.

KEY WORDS: REPRESENTATION, PLACE, TOWN. 